\title{
Suppliers' opportunity enactment through the development of valuable capabilities
}

\author{
Dr Kristian Philipsen \\ Associate Professor, \\ Department of Entrepreneurship and Relationship Management, \\ University of Southern Denmark, \\ Engstien 1, 6000 Kolding, Denmark \\ Tel. 6550 1376, Fax. 6550 1357, \\ E-mail: kp@sam.sdu.dk \\ Dr Torben Damgaard \\ Associate Professor, \\ Department of Entrepreneurship and Relationship Management , \\ University of Southern Denmark, \\ Engstien 1, 6000 Kolding, Denmark \\ Tel. 6550 1382, Fax. 6550 1357, \\ E-mail: torben@sam.sdu.dk \\ Dr Rhona E Johnsen ${ }^{1}$ \\ (corresponding author), \\ Senior Lecturer in International Marketing Strategy \\ Bournemouth University, The Business School, Institute of Business and Law, \\ Bournemouth House, Christchurch Road, Bournemouth, BH1 3LH, UK \\ Tel: +44 (0)1202967217 \\ Email: rjohnsen@bournemouth.ac.uk
}

\footnotetext{
${ }^{1}$ Corresponding Author: Dr Rhona E Johnsen, Senior Lecturer, The Business School, Institute of Business and Law, Bournemouth University, Bournemouth House, Christchurch Road, Bournemouth BH1 3LH, UK.

Tel: +44(0)1202967217 E-mail: rjohnsen@bournemouth.ac.uk
} 


\title{
Suppliers' opportunity enactment through the development of valuable capabilities
}

\begin{abstract}
Purpose - The contribution of this paper is the development and application of a theoretical framework to examine the connections between different types of suppliers, their capabilities and opportunities in customer relationships, and the illustration of these connections through the findings from empirical case studies of small and medium-sized suppliers in the metal industry in Denmark.
\end{abstract}

Methodology/approach - Multiple case studies involving seventeen small and medium-sized suppliers within the Danish metal industry were undertaken.

Findings - By focusing on the development of capabilities that are 'valuable' to customers in specific types of supply, small and medium-sized suppliers may improve their responses to opportunities in their customer relationships.

Research limitations/implications - Further investigation is needed on the longer-term impacts of valuable capabilities on opportunity enactment by suppliers, and the examination of key issues arising from these findings across different industries and countries.

Practical implications - Small and medium-sized suppliers, their customers and government agencies involved with suppliers should advocate and actively support the development of valuable capabilities to enhance the effectiveness of suppliers' relationship and network strategies and their potential to seize opportunities.

Originality/value - This study highlights that different types of suppliers require different types of current and future valuable capabilities to seize opportunities and sustain current customers or develop new customer relationships. 
Paper type: Research paper

Keywords: small-medium-sized suppliers, opportunities, capabilities, value, relationships.

\section{Introduction}

Few studies have been conducted from a relationship and network perspective that examine the connections between different types of small and medium-sized suppliers, their capabilities and opportunities in customer relationships. Different types of suppliers may require different current and future capabilities to enable them to seize opportunities and innovate within their relationships. However, relatively little is known about how smaller suppliers align their capabilities with those of customers to take advantage of opportunities (e.g. Håkansson and Ford, 2002). In this paper we take point of departure from the idea that a smaller supplier's capabilities can be developed in a number of ways, creating critical opportunities for development and innovation in its customer relationships. The paper examines how different types of small and medium-sized suppliers develop different current and future capabilities to harness opportunities in their customer relationships.

Previous research by Ritter (1999) investigated the impact of organisational antecedents on network capabilities or 'competencies' and found that the availability of internal resources, a network orientation in human resource management, the integration of the communications structure and openness of corporate culture between firms had positive impacts on their network capabilities. However, a review of the existing literature indicates that previous studies have tended to approach capability development in relationships and networks on a 
general network level and have not related it to the particular situation of different types of firms, nor specifically to the situation of small and medium-sized suppliers.

The focus on small and medium-sized suppliers in this study has been adopted to reflect the paucity of previous relationship and network research on how smaller firms develop 'valuable' capabilities and harness opportunities. In particular, the aim of this paper is to develop a more systematic understanding of how small and medium-sized suppliers perceive and take advantage of opportunities based on their approaches to developing 'valuable' capabilities.

The paper addresses this issue through a literature review combined with an empirical investigation involving seventeen case studies of three distinct types of small and mediumsized suppliers and their associated capabilities in customer relationships. The paper draws on insights from the strategic management literature and network theory, where the strategic options open to a supplier in a given situation are evaluated, not only through the network in which the firm is embedded and the expected opportunity, but also through an evaluation of whether the supplier has the right set of capabilities to take advantage of a certain opportunity in its relationships (Leonard-Barton, 1992; Johnsen and Ford, 2002).

The research question explored in this paper is therefore:

What are the 'valuable' capabilities that are developed by different types of small and medium-sized suppliers, and how do these capabilities enable them to take advantage of opportunities in their customer relationships? 


\section{A research situation: small and medium-sized suppliers in the Danish metal industry}

The empirical basis for this paper is a research project concerning small and medium-sized suppliers in the metal industry in Denmark called "Suppliers of Tomorrow". The suppliers at the centre of this project, similarly to others in many advanced economies, face increasing pressures for survival aggravated by their customers’ moves towards capturing advantages associated with the manufacturing capabilities and lower costs of Asian or North African suppliers (e.g. Harrison, 2004). Danish metal suppliers have faced problems in sustaining their long-term customer relationships in such circumstances and have seen an erosion of their opportunities as their capabilities no longer appear so valuable to their current customers. They are therefore faced with challenges of identifying and exploiting new opportunities in order to replace or expand their existing customer portfolios. The identification of these problems facing Danish metal suppliers gave rise to the research project that is the focus of this paper. The overall research project aimed to develop a better understanding of how opportunities in relationships with customers are perceived by small and medium-sized suppliers, and how they can be understood and analysed from a theoretical as well as a managerial perspective.

\section{Supplier types and their opportunities and capabilities}

A wide body of knowledge on capability development and opportunity enactment from many perspectives (e.g. resource-based view of capability development and entrepreneurship view 
of opportunity enactment) has been advanced in the literature over the last few decades (Wernerfelt, 1984; Rumelt, 1987; Barney, 1986, 1991; Grant, 1990; Prahalad and Hamel, 1990; Wickham, 2004; Shane, 2000; Eckhardt and Shane, 2003). However, few studies have sought to link and address these issues from a relationship and network perspective. This paper brings together and integrates these distinct areas of theory to address the paucity of research on capability development and opportunity enactment from the perspective of small and medium-sized suppliers in their customer relationships. The section starts with a critical review of relevant theories concerning suppliers. It then proceeds with a review of opportunity enactment theory and looks at and how different types of suppliers may perceive and take advantage of their opportunities in their customer relationships. Finally, a review of the literature on capability development and its role in relationships between suppliers and customers is presented.

\section{Types of suppliers and supply}

A number of authors from differing perspectives have been concerned with understanding, conceptualising and characterising the interaction between suppliers and customers. Amongst others, Webster (1992) describes a continuum of relationships between long-term 'partnerships' to short-term adversarial relationships. Whilst highlighting an understanding of the extremes of a continuum from markets to vertical integration, this approach also offers a basic model for understanding suppliers and their relationships with customers (Andersen and Christensen 1998:35). Araujo et al. (1999) observe that a dramatic shift has taken place in recent years from a transactional to relational-oriented approach to understanding how suppliers and customers engage with each other. However, although the relative importance 
may have shifted towards the relational-oriented approach, not all suppliers may be able to follow this strategy in all relationship situations (Ford et al, 2003). Customers may only have limited resources to handle suppliers, and may be unable to always fulfil the resourcedemanding requirements of the relational approach. Similarly, suppliers may have found benefits accruing to stable relationships with one or a few major customers, focusing many of their resources on one customer alone (Johnsen, 2005).

Many authors propose that both customers and suppliers need to have a balanced portfolio of different types of relationships that may provide them with a wider range of benefits (Araujo et al. 1999; Gadde and Snehota 1999; Blenker, Kristensen and Servais 2001). A number of different supplier portfolio models have been proposed in the literature. These are typically two-dimensional matrices for classifying multiple relationships for the purpose of balancing relationship investment relative to relationship intensity, and for guiding firms in appropriate relationship development and management tasks (e.g. Krapfel et al., 1991; Bensaou, 1999; Wynstra and ten Pierick, 1999). Bensaou (1999) suggests that portfolio models can enable firms to better choose the types of relationships required under different sets of 'external contingencies’ and how best to manage each relationship.

Research on relationship portfolios by relationship and network scholars has raised the issue of the applicability of such planning models for capturing the complexity of customersupplier relationships, by attempting to categorise complex relationships, e.g. Dubois and Pedersen (2002). Although useful in categorising relationships, there may be difficulties in choosing appropriate dimensions with which to assess relationships (Zolkiewski and Turnbull, 2002). Furthermore, research has highlighted that the rigid use of relationship 
portfolios may induce firms to exploit their power or avoid risks in relationships, thereby limiting their experience of developing inter-dependencies (e.g. Ritter, 2000).

Smaller suppliers are often not blessed with the advantages of many customer relationships and may have limited choice in one or a few major customers. Hence, portfolio models may not be the most appropriate methods for assessing relationship development for small and medium-sized suppliers and they may need to categorize their customer relationship options more narrowly. Although recent research has indicated that small and medium sized suppliers with a wider portfolio of customer relationships may be better able to cope with changes in their customer relationships and have a wider range of relationship opportunities (Johnsen, 2005), this may require a deliberate and long-term strategy to build such a broad portfolio. Thus, in building towards a portfolio approach, it may be more advantageous for smaller suppliers with fewer relationship choices to concentrate on their dominant relationship mode to achieve more focused developments in their customer relationships.

In proposing that smaller suppliers concentrate on their dominant relationship mode, this paper adopts the distinction between three types of suppliers proposed by Andersen and Christensen (1998) and Blenker, Kristensen and Servais (2001): standard goods suppliers, traditional suppliers and partnership suppliers. This framework was identified as most appropriate to this research because of its applicability to small and medium-sized suppliers and its grounding in previous studies concerning Scandinavian suppliers. The standard goods supplier is characterised by delivering standardised components and goods; the traditional supplier delivers customer-specified operations; the partnership supplier has a strategic value for customers and delivers goods developed together with the customer. This distinction has 
some drawbacks. First, suppliers often have many customers, and the research project "Suppliers of Tomorrow" has shown that in practice they seldom fit one of the types, but rather, are dominated by one, but also include elements from one or both of the other types. This is relevant because suppliers may deliver different kinds of supply, often customised to different types of customers.

Philipsen, Damgaard and Munksgaard (2004) suggest an approach to solving the problem of classifying suppliers by defining 'ideal types' of suppliers. In this paper the adoption of a distinction between different types of supply rather than different types of suppliers is proposed. Each type of supply is based on a bundle of capabilities. A supplier may deliver more than one type of supply and thus have the bundle of capabilities (or part of) behind two or three of the supplies. Damgaard and Munksgaard (2005) suggest that the distinction between a standard goods supplier, a traditional supplier and a partnership supplier is based on two main dimensions (with reference to Andersen and Christensen 1998; Møller, Momme and Johansen 2000): the degree of coordination and degree of knowledge exchange. The standard supplier has the lowest degree on both dimensions, the partnership supplier the highest, and the traditional type of supplier in-between. Rather than being degrees of, for example, coordination or knowledge exchange, the focus here is on different modes of supply. The two dimensions "coordination" and "knowledge exchange" describe the relationship between the supplier and the customer (and in a wider sense the relationships of the supplier, customer and third parties).

Araujo et al. (1999) are proponents of the existence of four main types of interface between suppliers and customers. Their starting point is how the customer and the supplier relate their 
resources to each other. The most important factor here is whether the supplier or customer understands each other's context. The first type of interface therefore applies when the customer and supplier do not know each other well. Neither the supplier nor the customer needs to know about the other party's context. The products exchanged are standardised. The second type of interface is when the buying firm prefers a customised product. Therefore, there needs to be some interaction and adaptation from both the supplier and the customer. When the buying firm prescribes the specification of the product, Araujo et al. (1999) suggest that this is a "specified interface”. "A third type of interface appears when the buyer's direction is based on the function of the product in its user context. Araujo et al. (1999) label this the "translation interface" because the supplier needs to translate the functional characteristics that the customer provides into a product. The fourth type of interface can be labelled “joint learning” because an open-ended dialogue exists between the supplier and customer. Both parties join their knowledge from the user and supplier contexts to develop product specifications together. In this double learning process both supplier and customer mutually specialise and relate to each other.

The descriptions of these types of interfaces supplement the understanding of the three types of suppliers defined above. In this paper we combine the last two types identified by Araujo et al. (1999); the "translation interface” and "joint learning”, as both are considered to be included in the "partnership supplier"-type. This has been done to build on the work of these authors in the specific context of small and medium-sized suppliers and their relationships with customers. We argue that in the case of smaller suppliers there is often a need for an ongoing "translation interface" as the small firm is dependent on its customer for support and approbation. Hence, there may be a melding of the translation interface and joint learning into 
one continuous phase in the case of small and medium-sized suppliers and their customer relationships.

\section{Suppliers’ opportunities}

In this paper the opportunity concept is examined from a relationship and network view. Hence, small and medium-sized suppliers' opportunities relate to how they use their existing capabilities to do something different with current customers, or build capabilities through a better or different type of relationship with existing/new customers. The opportunity concept has been a cornerstone within entrepreneurship research, but has received scant attention from relationship and network researchers. Notable exceptions in network research have examined opportunities from the point of view of change in the network and perceptions, or 'pictures' of the network (Håkansson and Ford, 2002; Holmen and Pedersen, 2003) to emphasise that a company can only develop and achieve change through interaction. Within entrepreneurship research, the outcome of previous actions (successes and failures) will be evaluated and the entrepreneur will take actions to adjust the opportunity, the resources and the organisation. An opportunity is defined by Wickham (2004) as:

"the gap left in a market by those who currently serve it. It represents the potential to serve customers better than they are being served at present. The entrepreneur is responsible for scanning the business landscape for unexploited opportunities or possibilities that something important might be done both differently from the way it is done at the moment and, critically, better than it is at the moment" (Wickham 2004:134, Wickham's emphasis). 
Hence, an opportunity is about offering something differently or better than those who currently serve a customer. This suggests that customers have to perceive that the new offer has greater value in some sense to be prepared to switch to the new offer.

Opportunity enactment concerns how "the salient features of an opportunity only become apparent through the ways that entrepreneurs make sense of their experiences." ... In the opportunity enactment perspective, opportunities are seen to emerge out of the imagination of individuals by their actions and their interactions with others.” (Gartner, Carter and Hills 2003:105). Thus, opportunity enactment relates to the ways in which firms are able to sense, seize and act upon their available opportunities and is linked to their interaction and relationship context.

\section{Suppliers and their capabilities}

The relationship and network literature has tended to focus on the co-operative aspects of capability development and stressed the interdependencies between firms as a driving force for creative capability generation. Research by Rosenbröijer (1998) and Gressetvold (2004) has drawn on the network approach to analyse how capability development occurs within the firm. Interaction in relationships may shape the capabilities of a firm, so capabilities can be understood in terms of how they are recognised and valued by counterparts in a relationship, and how their usefulness and contribution to the network is perceived. Thus, there is a need for further research to explore the interplay between relationships and capability development. 
There have been several studies in relationship and network literature that have attempted to explore the value inherent in, and value creation potential of, relationships (Wilson and Jantrania, 1994; Walter et al., 2001), with some researchers focusing specifically on the links between relationship 'value’ and firms' capabilities (e.g. Möller and Törrönen, 2003). Relationship value is an emerging concept, and as such, it is not easy to find a precise definition. Value and perceived value have received attention in a variety of schools within the literature, from consumer behaviour, strategy and industrial marketing. According to Möller and Törrönen (2003), some researchers define value primarily in monetary terms (e.g. Anderson et al., 1993; Anderson and Narus, 1999). However, other researchers highlight that non-financial advantages and sacrifices are as important in assessing the value of a relationship, for example, social bonds, knowledge inputs, managerial time spent, and capability development (Möller and Törrönen, 2003).

The strategic nature of relationships between suppliers and customers indicates that it is critical for firms to be able to assess the 'value creation' potential of their counterparts. It has been suggested that the value of a supplier to its counterparts may often be evaluated through examining its capabilities, but that these are often based on a combination of several combined organisational capabilities that are not easy to assess, as they may, at least partly, be tacit (ibid.). Thus, it seems important that a supplier is able to demonstrate the value potential of its capabilities within its relationships, to enable its counterparts to assess its potential contribution to the relationship. Thus, capability developments of suppliers may have an important role within the overall development of value potential in their relationships. Valuable capabilities are defined in this paper as those that may derive internally and through 
relationships and make a significant contribution to the supplier-customer relationship in the customer's eyes.

In order to take advantage of identified opportunities, suppliers need to understand the distinct requirements of their current or potential customers and how these should be translated into internal capability development, or access to external capabilities across a number of areas e.g. technological, human, managerial systems and cultural interaction capability (e.g. Leonard-Barton, 1992; Johnsen, 2005). Furthermore, suppliers' capabilities need to be perceived as valuable by customers, in excess of those of the supplier's network counterparts, in order to enable opportunity enactment in relationships with current customers.

Granstrand et al. (1997) have argued the case for distributed capabilities. In their view (ibid.), large firms have been spreading their capabilities beyond their distinctive core, including "the capacity to improve and to co-ordinate change in complex production systems and supply chains as well as to explore and exploit emerging new technologies.” (pp. 15-16). Hence, this view implies that the management of the critical network relationships that form part of, and add value to, a firm's capabilities and the ability to leverage capabilities in a complex network of companies - or 'network competence' - is itself a critical capability (Ritter and Gemünden, 2004).

Established capabilities indicate to other firms that a company has the potential to be a strong contributor to knowledge development, creativity and innovation within relationships. Without the types of capabilities that are considered to make an important contribution in relationships, and are seen as valuable and distinctive by the other party, skills, knowledge 
and resources possessed by the firm may be considered to be 'hollow' capabilities (Chesbrough and Teece, 1996). Interaction with another party in a relationship will determine the usefulness of a firm's capabilities and will define the way in which these capabilities develop. To create valuable capabilities a firm must therefore consider how it will be viewed in relationships and how its capabilities will contribute to further knowledge development by combining with the capabilities of the other party in the relationship.

The importance of possessing core capabilities for a firm's ability to take advantage of opportunities has been widely discussed in the strategy literature using various concepts such as core competencies (Hamel and Prahalad, 1990), core capabilities and rigidities (LeonardBarton, 1992) and dynamic capabilities (Teece, Pisano and Shuen 1997; Teece, 1998). All these concepts are based on the assumption that the firm operates as a discrete organisation. In this paper the focus is on a network and relationship approach encompassing interaction between small and medium-sized suppliers and their customers. This raises the need for understanding capabilities in networks (Ritter, 1999) and relationships (Johnsen, 2005) and to develop an understanding of not only the capabilities resident in firms, but also those present in the relationships between suppliers and customers.

The seminal work of Leonard-Barton (1992) provides a foundation for understanding the set of capabilities that may be resident within firms. She argues that capabilities encompass four basic dimensions: 1) Skills and knowledge base (firm-specific techniques and scientific understanding embodied in employees); 2) technical systems (information and knowledge embedded in technical systems and procedures); 3) managerial systems (formal and informal ways of creating knowledge through e.g. networks, and controlling knowledge through e.g. 
incentive systems and reporting structures); 4) values and norms (the value assigned within the company to the content and structure of knowledge, means of collecting knowledge and controlling knowledge).

If capabilities are considered to be of strategic importance to a firm, they are labelled "core". Leonard-Barton (1992, p. 114) argues: “All four dimensions of core capabilities reflect accumulated behaviours and beliefs based on early corporate success. One advantage of core capabilities lies in this unique heritage, which is not easily imitated by would-be competitors."

An analysis of the four dimensions of capabilities, their interdependent development and the ways in which capability development are managed may have an important bearing on relationships. Suppliers may draw upon their capabilities to enable them to change their position in their relationships with customers and in the wider network (Johnsen, 2005). It therefore appears critical for suppliers to have an understanding of the ways in which capabilities are developed in relation to, or in conjunction with, their relationship counterparts, and what types of capabilities are most valued by customers.

Thus, it is necessary to understand the full implications for small suppliers involved in different types of supply of the need to build capabilities that enable them to grasp specific opportunities by better aligning their capabilities with specific customers and their current or potential needs, contributing not only to their own knowledge, but to that of their relationships. 


\section{Conceptual development: types of supply and suppliers and the links to capability and opportunity}

The conceptual developments in this paper are founded on the premise that a clearer view of how different types of suppliers perceive and take advantage of opportunities in their customer relationships may be achieved by understanding their approaches to developing 'valuable' capabilities. To be able to take advantage of new opportunities, a supplier has to possess or be able to develop capabilities that are perceived as valuable by its customer. Capability developments in a supplier may take place across a range of capability areas, focusing on intangible as well as tangible aspects of capabilities. In support of the discussions that follow, Table I sets out a framework to examine three types of supplies and relates these to supplier capabilities and opportunities in their customer relationships.

Take in Table I

The typology in Table I is based on the types of relationships that a small and medium-sized supplier may have with its customers. The basis of this typology is grounded in the arguments built earlier in this paper concerning the advantages for smaller suppliers with fewer relationship choices to concentrate on their dominant relationship mode to achieve more focused capability developments in their customer relationships. In proposing that smaller suppliers concentrate on their dominant relationship mode, the typology adopts the distinction between the three types of identified supplies: standard goods, traditional and partnership supplies. Supplies are exchanged either under market conditions or within collaborative 
arrangements with markets as well as cooperative institutions. The supplier's valuable capabilities change according to the type of supply in which they engage. When the supply is of importance to customers it is viewed in terms of a valuable capability. However, the capability to deliver standard goods supplies, traditional supplies and partnership supplies differs according to the handling of activities within and across actors. In the interplay between a supplier's capabilities and the customers that it serves opportunity enactment may take place.

Alongside each characteristic in the left column of the table the type of capability required for each type of supply is highlighted: SKB: skills and knowledge base; TS: technical system, MS: Managerial system; and VN: values and norms. If some of these capabilities are directly related to relational or network elements, an " $\mathrm{R}$ " is placed in the table. The labels concerning capabilities are tentative and their main purpose is to illustrate that the bundle of capabilities changes across the type of supply and thus links together capabilities and opportunities with certain types of supply in existing relationships with customers. 


\section{Table I Three ideal types of supply related to small and medium-sized supplier capabilities and opportunities in customer relationships}

\begin{tabular}{|c|c|c|c|}
\hline & Standard goods supply & \begin{tabular}{|l|} 
Traditional supply \\
\end{tabular} & Partnership supply \\
\hline \multicolumn{4}{|c|}{ DESCRIPTIONS OF SUPPLY CHARACTERISTICS: } \\
\hline $\begin{array}{l}\text { Products and } \\
\text { services delivered by } \\
\text { the supplier }\end{array}$ & $\begin{array}{l}\text { Standard products or services which } \\
\text { can be ordered from a catalogue or } \\
\text { order list }\end{array}$ & $\begin{array}{l}\text { Products, processes and services } \\
\text { developed from customer } \\
\text { specifications/ drawings }\end{array}$ & $\begin{array}{l}\text { Customer-adapted products, services, } \\
\text { processes and systems developed in } \\
\text { cooperation between supplier and } \\
\text { customer }\end{array}$ \\
\hline \multicolumn{4}{|c|}{ REQUIRED CAPABILITIES FOR SUPPLIERS } \\
\hline $\begin{array}{l}\text { Managerial systems, } \\
\text { skills and knowledge } \\
\text { base, values and } \\
\text { norms }\end{array}$ & $\begin{array}{l}\text { Technical skills in production } \\
\text { processes and materials. } \\
\text { Efficiency in production. } \\
\text { Internally focused }\end{array}$ & $\begin{array}{l}\text { Eventual access via network: } \\
\text { Technical skills in production } \\
\text { processes and materials. } \\
\text { Efficiency in production. } \\
\text { Governance capability. } \\
\text { Monitor and manage the flow of } \\
\text { information, material, components and } \\
\text { products. }\end{array}$ & $\begin{array}{l}\text { Eventual access via network: } \\
\text { Technical skills in production } \\
\text { processes and materials. } \\
\text { Efficiency in production. } \\
\text { Governance capability. } \\
\text { Monitor and manage the flow of } \\
\text { information, material, components and } \\
\text { products. } \\
\text { Capability in management of } \\
\text { relationships and collaboration. }\end{array}$ \\
\hline \multicolumn{4}{|c|}{ DESCRIPTION OF CAPABILITIES FOR EACH CHARACTERISTIC OF SUPPLY } \\
\hline $\begin{array}{l}\text { Time horizon and } \\
\text { focus of the } \\
\text { relationship between } \\
\text { supplier and } \\
\text { customer }\end{array}$ & $\begin{array}{l}\text { Short } \\
\text { Focus on cash flow } \\
\text { Capabilities: TS }\end{array}$ & $\begin{array}{l}\text { Medium } \\
\text { Focus on investments in technical ROI } \\
\text { Capabilities: TS }\end{array}$ & $\begin{array}{l}\text { Long-term, strategic cooperation } \\
\text { Focus on investments in relationship, } \\
\text { long term ROI } \\
\text { Capabilities: TC and RTC }\end{array}$ \\
\hline $\begin{array}{l}\text { Contact between } \\
\text { supplier and } \\
\text { customer }\end{array}$ & $\begin{array}{l}\text { Supplier has limited or no contact with } \\
\text { customer. Seldom or never meet. } \\
\text { Capabilities: MS }\end{array}$ & $\begin{array}{l}\text { Supplier has limited cooperation with } \\
\text { customers. They meet from time to } \\
\text { time. } \\
\text { Capabilities: MS, RMS }\end{array}$ & $\begin{array}{l}\text { Supplier has close cooperation with } \\
\text { customers. They meet regularly and } \\
\text { work together through cross- } \\
\text { fertilisation of teams and exchange of } \\
\text { personnel. } \\
\text { Capabilities: RMS, MS }\end{array}$ \\
\hline $\begin{array}{l}\text { Supplier's degree of } \\
\text { coordination with } \\
\text { customer }\end{array}$ & $\begin{array}{l}\text { Low } \\
\text { Capabilities: MS and VN }\end{array}$ & $\begin{array}{l}\text { Medium } \\
\text { Capabilities: RMS and VN and SKB }\end{array}$ & $\begin{array}{l}\text { High to very high degree of } \\
\text { coordination and integration of } \\
\text { management structures and i.e. } \\
\text { logistics or production systems. } \\
\text { Capabilities: RMS and VN and SKB }\end{array}$ \\
\hline $\begin{array}{l}\text { Learning processes } \\
\text { conducted between } \\
\text { supplier and } \\
\text { customer }\end{array}$ & $\begin{array}{l}\text { No or few/sporadic } \\
\text { Capabilities: SKB }\end{array}$ & $\begin{array}{l}\text { The supplier learns from the customer } \\
\text { Capabilities: RSKB }\end{array}$ & $\begin{array}{l}\text { Mutual, inter-dependent learning } \\
\text { processes. } \\
\text { Capabilities: RSKB }\end{array}$ \\
\hline $\begin{array}{l}\text { Dependence of } \\
\text { exchange of } \\
\text { information between } \\
\text { supplier and } \\
\text { customer } \\
\end{array}$ & $\begin{array}{l}\text { Low } \\
\text { Capabilities: SKB } \\
\end{array}$ & Capabilities: SKB and RMS & $\begin{array}{l}\text { Very high inter-dependence. } \\
\text { Capabilities: RSKB and RMS }\end{array}$ \\
\hline $\begin{array}{l}\text { Sharing of resources } \\
\text { between supplier } \\
\text { and customer }\end{array}$ & $\begin{array}{l}\text { Separate resources. } \\
\text { Capabilities: TS }\end{array}$ & $\begin{array}{l}\text { A few resources are shared. } \\
\text { Capabilities: TS }\end{array}$ & $\begin{array}{l}\text { Extensive sharing of joint investments, } \\
\text { tasks and activities based on shared } \\
\text { resources. } \\
\text { Capabilities: TS and RTS and RMS }\end{array}$ \\
\hline $\begin{array}{l}\text { Dominant form of } \\
\text { marketing for } \\
\text { supplier }\end{array}$ & $\begin{array}{l}\text { Traditional marketing approach. } \\
\text { Capabilities: VN and SKB }\end{array}$ & $\begin{array}{l}\text { Reverse marketing approach. } \\
\text { Capabilities: VN and SKB }\end{array}$ & $\begin{array}{l}\text { Interactive marketing approach. } \\
\text { Capabilities: VN and SKB }\end{array}$ \\
\hline
\end{tabular}




\begin{tabular}{|c|c|c|c|}
\hline & Standard goods supply & Traditional supply & Partnership supply \\
\hline \multicolumn{4}{|c|}{ DESCRIPTIONS OF SUPPLIERS' OPPORTUNITIES: } \\
\hline $\begin{array}{l}\text { Gathering } \\
\text { information about } \\
\text { opportunities }\end{array}$ & $\begin{array}{l}\text { Market research i.e. by segmentation of } \\
\text { customers in groups with the same } \\
\text { types of needs. } \\
\text { Capabilities: SKB and VN }\end{array}$ & $\begin{array}{l}\text { Through new tasks or changed } \\
\text { specifications to products and service } \\
\text { by customers. } \\
\text { Capabilities: SKB and VN and RSKB }\end{array}$ & $\begin{array}{l}\text { Interactive marketing. } \\
\text { Lead users. } \\
\text { Capabilities: RMS, RVN, RSKB }\end{array}$ \\
\hline $\begin{array}{l}\text { Expected shorter- } \\
\text { term opportunities }\end{array}$ & $\begin{array}{l}\text { Products clearly related to the existing } \\
\text { technology/ capability base. } \\
\text { Core rigidities/capabilities: TS and MS }\end{array}$ & $\begin{array}{l}\text { Vary according to customers' needs } \\
\text { and demands. } \\
\text { Core rigidities/capabilities: TS and MS }\end{array}$ & $\begin{array}{l}\text { Vary according to both the customer } \\
\text { and supplier's mutual interests in } \\
\text { projects. } \\
\text { Core rigidities/capabilities: TS and } \\
\text { RMS }\end{array}$ \\
\hline $\begin{array}{l}\text { Expected } \\
\text { opportunities in the } \\
\text { medium to long term }\end{array}$ & $\begin{array}{l}\text { Develop new products based on } \\
\text { existing capabilities for existing/ new } \\
\text { markets. } \\
\text { Capabilities: TS }\end{array}$ & $\begin{array}{l}\text { Develop products to new specifications } \\
\text { for customers. } \\
\text { Capabilities: TS, RMS }\end{array}$ & $\begin{array}{l}\text { Opportunities dependent on chosen } \\
\text { strategy of customers. } \\
\text { Capabilities: RMS }\end{array}$ \\
\hline $\begin{array}{l}\text { Rigidities and } \\
\text { limitations }\end{array}$ & $\begin{array}{l}\text { Inability to understand changes in } \\
\text { customer needs because of lack of } \\
\text { close dialogue. } \\
\text { Change in strategic course towards } \\
\text { other types of supply (or other strategic } \\
\text { options) restricted by lack of } \\
\text { capabilities and experiences in } \\
\text { governance and logistics. } \\
\text { Rigidities: TS. SKB, VN and MS }\end{array}$ & $\begin{array}{l}\text { Lock-in to existing customers. If the } \\
\text { supplier is able to offer its products } \\
\text { and services to several potential new } \\
\text { customers the lock-in gives limitations } \\
\text { sets by the existing capabilities. If the } \\
\text { suppliers have only limited } \\
\text { possibilities to attract/be chosen by } \\
\text { new customers the lock-in primarily } \\
\text { concerns the supplier. } \\
\text { Rigidities: TS. SKB, VN and RMS }\end{array}$ & $\begin{array}{l}\text { Suppliers' investments in cooperation } \\
\text { with certain customers make substantial } \\
\text { commitment to and dependence on the } \\
\text { customer choosing the right course of } \\
\text { action. }\end{array}$ \\
\hline
\end{tabular}

\section{Research methodology}

The "Suppliers of Tomorrow" research project ${ }^{2}$ involved case studies of seventeen small and medium-sized suppliers within the metal industry in Denmark and was conducted over a period of two years. Multiple case studies (Yin, 2003) were chosen for this study to enable both an in-depth examination of each case, whilst also seeking to identify the unique situations that distinguished one case from another.

The Danish metal industry was an appropriate focus for the study as it involves many small and medium-sized suppliers that have experienced recent changes in their business network,

\footnotetext{
${ }^{2}$ The research project had three over-arching objectives: 1) To identify different types of suppliers (their situations, capabilities and relationships); 2) To identify and analyse the pressure for changes from the environment/network for the different types of suppliers; 3) To analyse possible opportunities and strategic options for each type of supplier.
} 
requiring them to seek out new opportunities with existing or new customers (Philipsen, Damgaard and Munksgaard, 2004). Thus, the chosen cases were involved in broadly the same industry sector and shared similar backgrounds and problems in their customer relationships and network. The case firms could all be described as inhabiting either a 'first-tier' or 'second-tier' supplier position in their business network. Moreover, the size of the suppliers conformed to European Commission definitions (2002) of small-medium-sized firm size (up to 250 employees).

The data was collected through qualitative in-depth interviews, meetings and observations. Each firm was interviewed several times over the research period to be able to identify any significant changes taking place in their situation. The research project builds on an existing theoretical framework for examining different types of suppliers (Philipsen, Damgaard and Munksgaard, 2004). The framework was validated through a series of pilot interviews with suppliers prior to conducting the main body of data collection. The respondents comprised directors and managers of the supplier firms. The principal criterion for determining the respondents was their knowledge and experience of capability development and customer relationships. All interviews for the study were tape-recorded and transcribed.

The unit of analysis for the empirical work was the supplier firm and its perspective on its capability developments and opportunities in relationships. The analytical strategy adopted in this study was to seek to relate data to the research question through the conceptual framework of types of supply and suppliers' capabilities, thus displaying and reducing the data. Furthermore, as this study was exploratory, and therefore concerned with understanding 
the unique situations and experiences of the suppliers, a level of explanation building (Yin, 2003) was also required in the drawing of conclusions and verification.

Conceptually clustered and role ordered matrices (Miles and Huberman, 1984), were used as coding frameworks to reduce, structure and analyse the data, whereby the responses from interviewees were summarised, interpreted and tabulated from the transcripts, according to the themes and issues covered in the interviews. This enabled intra-case comparisons and highlighted similarities and differences between responses. Cross-case comparisons and the identification of patterns and synthesis were achieved through the development of metamatrices ordered by cases (Miles and Huberman, 1984). These enabled the researchers to interpret the picture found across the case studies, identifying similarities and divergences across the cases and drawing conclusions on the empirical study.

\section{Discussion of findings}

The overarching findings of the study concern the ways in which the small and medium-sized suppliers' opportunities and capabilities differed in their customer relationships according to the dominant type of supply on which they focused. The suppliers were found to possess advantages related to a clearer focus and application of their capabilities by concentrating on one dominant type of supply, particularly in the standard goods and traditional supply categories . This meant that these suppliers' capability developments could be geared to the perceived value of customers and that opportunities were more tangible and clear to the suppliers. So, by concentrating on one type of supply small and medium-sized suppliers in the 
study were able to make better capability development choices and take important decisions more quickly when opportunities with customers were presented. In addition, the suppliers were able to personalise their responses to customers and gain confidence in their relationship sphere.

However, the focus on one type of supply and the associated capabilities and opportunities in customer relationships meant that the small and medium-sized suppliers tended to have established 'comfort zones' in dealing with the same types of customers that they had done throughout their history. Although the focus on one dominant type of supply meant that some partnership suppliers had used this as a launch pad in achieving considerable success in working towards the development of a more diverse portfolio of customers, these suppliers had to confront the need to establish priorities, identify how best to manage in new relationships, and at the same time balance a portfolio of different customers needing distinctly different capabilities. For small and medium-sized suppliers used to dealing with a limited number of large customers this was a considerable challenge that required them to become more agile, independent and confident in their approaches to capability development and opportunity enactment with customers.

In the following section three case studies from the seventeen involved in the study are highlighted and used to illustrate how opportunities and capabilities differed according to the three types of supply identified in the conceptual framework. This approach has been adopted as the findings across the seventeen case studies provided support for the conceptual framework and the three cases used to illustrate the suppliers' situations are typical of the findings across the cases. Overall six of the cases were typical of the standard goods supply, 
five traditional supply and six demonstrated partnership supply, as highlighted in the conceptual framework in Table I. Therefore the three cases discussed below are representative of the findings across the piece from each of the subsets outlined in the conceptual framework.

In the following discussions emphasis is placed on how the suppliers' capabilities differ according to the distinct ways in which they are related to other actors in the network. The opportunity of each type of supplier is described either in terms of using its existing capabilities to do something different with current customers, or building capabilities through a better or different type of relationship with existing/new customers. This may be evident in the supplier developing its own specialist capabilities or through reconfiguration of the extant capabilities resident in the network. These issues are discussed in the case illustrations that follow.

\section{Standard goods supply: Case Illustration BMWorks}

BMWorks is a machine manufacturer involved in traditional chip cutting, bending and punching, to produce standard components in various metallic materials. The majority of the company's product portfolio consists of standard components made to stock and sold as stock goods. The company's market is very heterogeneous as its customers operate in very different lines of business. To some customers, BMWorks functions as a capacity supplier. BMWorks is a standard supplier because its relations with its customers can be characterised as simple transactions, with the customers ordering from the company's catalogue, requiring a few minor specifications, if any. BMWorks seldom meets with customers and it is never involved 
in customers' development activities. The company does not take part in customers' projections or drawings and deliveries are agreed upon from order to order.

The opportunities for the standard goods supplier can be separated into two forms: improving the capabilities that they already possess or developing new capabilities to handle new problems. Through developing the technical capabilities in the company and through the development of production and process capabilities, the supplier can develop new processes and products. As a result, the suppliers' capabilities are more valuable to existing customers or new customers. For example, the provision of machine suppliers' information, which competing suppliers seldom offer, has created a path to opportunities with customers.

The standard goods supplier can also seek opportunities through developing capabilities related to a change of supplier type, e.g. towards becoming a traditional supplier. Through the development of governance capabilities they may better adapt to different customers' needs. For example, governance in order to deliver just-in-time solutions, or to make processes more customer-adapted to better fit their production and product portfolio.

\section{Traditional supply: Case Illustration JGL}

JGL engineering works makes simple and complex turning parts in materials such as aluminium, brass, steel, stainless steel and different types of synthetic materials. The company primarily sells to the Danish market to globally represented customers, but also exports to Northern Germany. JGL engineering works can be defined as a traditional supplier, as the 
company primarily manufactures components on the basis of customers' drawings and projections. The company is neither involved in, nor actively contributes to customers' product developments. Customer contact is formal and controlled by top management at JGL. Contact people within customers' firms are primarily based in the purchasing or production department. In general, customer relations are characterised by focusing on price, and customers are frequently unwilling to negotiate. The success of JGL engineering works is often dependent on its close relationships built up with customers' purchasing departments.

With a few more strategically-focused customers, JGL's relationships can be characterised somewhat differently. The supplier has an extended collaboration with one customer where JGL delivers directly to the customer's stock without the customer being involved in entry quality control, and all deliveries to that customer are based on the customer's predictions. In this relationship, JGL stocks on the basis of the customer's forecast. JGL does not have formal relationships with their own suppliers or other partners. They would rather turn down an order than send it to a collaboration partner.

For the traditional supplier, improving what they already do means improving governance capabilities and production and process capabilities. For the traditional supplier, developing new capabilities to handle new problems takes the form of the development of relationship and collaboration capabilities. The opportunity in this situation, lies in better governance or changing to a different type of supply, by aspiring to the opportunities of the partnership supplier, through the development of relational and collaborative capabilities. Alternatively, traditional suppliers may focus inwards to gain efficiency in processes and production, thus heading more towards the situation of the standard goods supplier. 
In conclusion, opportunities for the traditional supplier can be obtained through better governance, inward movement towards the standard goods supplier's efficiency in technical skills, or outwards towards a partnership, where relational and collaborative capabilities serve as the umbrella for further development of opportunities with customers.

\section{Partnership supply: Case Illustration IntercityCom}

IntercityCom produces and sells communication systems for public transport. The end customers are international manufacturers of means of transportation, such as buses and trains. The most important and threatening competitor in this market often wins on price, but the competitor's technological platform is not as highly developed as that of IntercityCom and the competitor often faces technological problems.

IntercityCom can be defined as a partnership supplier, as the company is an active partner in its customers' development activities and co-develops its customers’ products. IntercityCom has moved towards the development of closer relationships with customers and other partners in recent years. Its customer relationships are characterised by informality and closeness with

several different departments in the customers' organisations. Over the years, several relationships with customers have contributed positively to developing IntercityCom's technological capabilities. Moreover, customer relationships have contributed to both broadening the scope and focus of IntercityCom's product portfolio. Recently, the supplier has decided to develop a modularised product portfolio to meet customers' demands for 
specialised products and to achieve cost-savings. This development project is accomplished in co-operation with a strategic customer and selected suppliers.

For several years, selected suppliers to IntercityCom have been involved as strategic collaboration partners. This has led to direct relations between the suppliers of IntercityCom and their customers. This sets special demands for co-ordination and securing knowledge flows between all partners. Although this co-ordination is very resource-demanding and timedemanding, the benefits from these partnerships are highly valued by IntercityCom. Therefore, IntercityCom constantly nurtures their strategic relationships and pursues the development of similar new relations that may complement the company's product portfolio.

Recently IntercityCom has experienced pressure for even higher co-ordination, advanced learning processes and integration in customers' product developments. An indication of this is the growing demand to co-ordinate more and more activities across company borders to reach a still higher focus on the final goods.

As a partnership supplier, relationship management and collaborative capabilities are essential in reaching a better position in the network. These capabilities are the umbrella under which technical capabilities are developed across partner companies as well as in the supplier's own company. For this type of supplier, a stream of opportunities come from the wider network through co-operation and joint developments or projects with customers and other parties in the network.

\section{Conclusions}


The preceding discussions have highlighted that different types of suppliers need different types of current and future capabilities to seize opportunities with customers. The three illustrative cases have served to demonstrate that standard goods supply tended to be associated with tangible technological and human capability developments. Traditional supply and partnership supply required an emphasis on less tangible forms of capability (LeonardBarton, 1992), with an increasing focus on managerial and relational aspects of capability development as firms moved along a continuum from traditional to partnership supply.

No one type of supplier was inherently superior in terms of the ways in which it seized its opportunities or developed its capabilities in customer relationships. Indeed, each different type of supplier had the potential to develop a range of capabilities that would give access to opportunity development with new customers. However, capability developments could be successfully or unsuccessfully managed (Bensaou, 1999). Success in capability developments for suppliers could be achieved by matching the required capabilities with the type of supply involved. Moreover, close involvement with customers and other actors within the network ensured that capability developments within suppliers were driven by the demands or preferences of their network counterparts as much as those of the suppliers themselves, ensuring that value to network counterparts was factored into capability development plans (Johnsen, 2005). The matching of opportunities with different customers and other network counterparts also enabled the capability developments of suppliers to be made more transparent, thus contributing to the diffusion of information and understanding about a particular supplier's capabilities and leading to a stream of opportunities coming towards the supplier from the network. 
In conclusion, the findings indicate that the development of capabilities that are valuable to customers in a dominant type of supply may enable opportunity enactment by small and medium-sized suppliers in their relationships. Thus, the development of valuable capabilities may enable small and medium-sized suppliers to improve their responses to opportunities in their current or potential customer relationships, by giving them a stronger or wider capability base within the firm and giving them more assurance of their longer-term survival in customer relationships the confidence to take advantage of emerging opportunities in the network. The required capabilities to survive and prosper may be present internally within the supplier or accessed via the supplier's network. Thus, both internal capabilities and those that may be accessed externally in the network are crucial in enabling small and medium-sized suppliers to harness opportunities that currently exist or have the potential to develop.

Finally, the development of valuable capabilities may have not only positive, but negative aspects. Suppliers need to be aware of the perils associated with capability rigidities (Hamel and Prahalad, 1990; Leonard-Barton, 1992). By focusing only on capabilities that are predominantly perceived as valuable to their network counterparts, suppliers may risk losing the potential to develop creative, leading-edge capabilities that could potentially distinguish their offerings from competitors. This in turn could lead to the supplier being ill-prepared for seizing opportunities presented in the future in new relationship situations and markets.

\section{Managerial implications}


The findings of this study have implications for smaller suppliers, their customers, other organisations in the network and government agencies involved with smaller suppliers. It is important to for such organisations to advocate and actively support the development of valuable capabilities in small and medium-sized suppliers to enhance their ability to seize opportunities in customer relationships and the wider network of organisations with which they are involved.

This paper has advanced arguments about how valuable capabilities may affect the harnessing of opportunities by different types of small and medium-sized suppliers in their customer relationships. The way in which core capabilities are defined, to be strategically important, may be too narrow a concept to fully understand the nature of capabilities from a smaller supplier's perspective. Small and medium-sized suppliers may be unable to possess great numbers of important capabilities and non-core capabilities tend to be excluded in any capability assessment by customers. There may also be problems with describing core capabilities in generic terms - when they are to some extent firm-specific and relationshipspecific. Nevertheless, this study has revealed some paths open to small and medium-sized suppliers and has suggested that the development of valuable capabilities is a prerequisite to take advantage of opportunities in customer relationships.

Managerial implications include the importance for small and medium-sized suppliers of developing an understanding of the implications of their supplier type for their approaches to developing valuable capabilities and capturing opportunities in customer relationships. Furthermore, the importance of seizing the strategic opportunities arising from different elements of capability development is critical for suppliers in maintaining their current 
customer relationships or developing new relationships in the network. Thus, developing the capability to take advantage of opportunities may be a critical skill for small and mediumsized suppliers. As this study involved case studies of smaller suppliers in only one industry and one country; the Danish metal industry, avenues for further research include exploring the longer-term impacts of valuable capabilities on opportunity enactment by suppliers, and the examination of key issues arising from the findings across different industries and countries.

\section{References}

Andersen, P. H. \& Christensen, P. R. (1998) Den Globale Udfordring - danske underleverandørers internationalisering. København, Eksportfremmerådet, Kbh.

Anderson, J.C., Jain, D.C. and Chintagunta, P.K. (1993) Customer value assessment in business markets; a state-of-practise study, Journal of Business-to-Business Marketing, Vol. 1 No. 1, pp. 3-29.

Anderson, J.C. and Narus, J.A. (1999) Business market management: understanding, creating and delivering value, Prentice Hall, Englewood Cliffs.

Araujo, L., Dubois, A. and Gadde, L.E. (1999) Managing Interfaces with Suppliers, Industrial Marketing Management, Vol. 28 No. 5 pp. 497-506.

Barney, J. (1986) Strategic factor markets: expectations, luck, and business strategy, Management Science, Vol. 4 No. 10, pp. 1231-1241. 
Barney, J. (1991) Firm resources and sustained competitive advantage, Journal of Management, Vol. 17 No. 1, pp. 155-171.

Bensaou, B.M. (1999) Portfolio of Buyer-Seller Relationships, Sloan Management Review, Vol. 40, Summer, pp. 35-44.

Blenker, P., Kristensen, P.S. and Servais, P. (2001) Supplier selection and portfolio strategy, in Freytag, P.V. (Ed.) Portfolio Planning in a Relationship Perspective, Forlaget Thomson, Copenhagen, pp. 61-91.

Chesbrough, H.W. and Teece, D.J. (1996) When is virtual virtuous? Organizing for innovation, Harvard Business Review, January-February, pp. 65-73.

Damgaard, T. and Munksgaard, K.B. (2005) Tidens Leverandør. Et dialogvæerktøj til underleverandørers kompetenceudvikling (Suppliers of Tomorrow. A dialogue toolbox for the development of suppliers' capabilities), Center for Small Business Research, CESFO, University of Southern Denmark.

Dubois, A. and Pedersen, A-C. (2002) Why relationships do not fit into purchasing portfolio models - a comparison between the portfolio and industrial network approaches, European Journal of Purchasing and Supply Management, Vol. 8 No. 1, pp. 35-42. 
Eckhardt J.T. and Shane, S.A (2003) Opportunities and entrepreneurship, Journal of Management, Vol. 29 No. 3, pp. 333-349.

Ford, D., Gadde, L.-E., Håkansson, H. and Snehota, I. (2003) Managing Business Relationships, $2^{\text {nd }}$ edition, John Wiley, Chichester.

Gadde, L.E. and Snehota, I. (1999) Making the Most of Supplier Relationships, Industrial Marketing Management, Vol. 29 No. 4, pp. 304-317.

Gartner, W.B., Carter, N.M. and Hills, G.E. (2003) The language of opportunity, in Steyaert, C. and Hjort, D., New Movements in Entrepreneurship, Edward Elgar, Cheltenham.

Grandstrand, O., Patel, P. and Pavitt, K. (1997) Multi-technology corporations: why they have ‘distributed’ rather than 'distinctive core’ competencies. California Management Review, Vol. 39 No. 4, pp. $1-19$.

Gressetvold, E. (2004) Product development - effects on a company's network of relationships, PhD Thesis, NTNU, Trondheim, Norway.

Grant, R. M. (1990) The resource-based theory of competitive advantage, California Management Review, Vol. 33 No. 3, pp. 114-135.

Håkansson, H. and Ford, D. (2002) How should companies interact in business networks?, Journal of Business Research, Vol. 55, pp. 133-139. 
Harrison, D. (2004) Is a long-term business relationship an implied contract? Two views of relationship disentanglement, Journal of Management Studies, Vol. 41 No. 1, pp. 107-125.

Holmen, E. and Pedersen, A.C. (2003) Strategizing through analyzing and influencing the network horizon, Industrial Marketing Management, Vol. 32, pp. 409-418.

Johnsen, R.E. (2005) Smaller Supplier-Larger Customer Relationships: An Exploration of Asymmetry, PhD Thesis, University of Bath School of Management, Bath, UK.

Johnsen, R.E. and Ford, D. (2002) Developing the Concept of Asymmetrical and Symmetrical Relationships: Linking Relationship Characteristics and Firms’ Capabilities, Proceedings of the $18^{\text {th }}$ Annual IMP Conference, ESC Dijon, France.

Krapfel, R., Salmond, D. and Spekman, R. (1991) A strategic approach to managing buyerseller relationships, European Journal of Marketing, Vol. 25 No. 9, pp. 22-37.

Leonard-Barton, D. (1992) Core Capabilities and Core Rigidities: A Paradox in Managing New Product Development, Strategic Management Journal, Vol. 13 Summer, pp. 111-125.

Miles, M. and Huberman, A. (1984) Qualitative data analysis: a sourcebook of new methods, Sage, London. 
Møller, M.M., Momme, J. and Johansen, J. (2000) Supplier Segmentation in Theory and Practice - Towards a competence perspective, Working Paper, Aalborg University.

Möller, K. and Törrönen, P. (2003) Business suppliers’ value creation potential. A capabilitybased analysis, Industrial Marketing Management, Vol. 32 No. 2, pp. 109-118.

Philipsen, K., Damgaard, T. and Munksgaard, K. (2004) The Paradox of Opportunity and Limitations for Suppliers, Proceedings of the $20^{\text {th }}$ IMP Conference, Copenhagen Business School, Denmark.

Prahalad, C.K. and Hamel, G. (1990) The core competencies of the corporation, Harvard Business Review, May-June, pp. 71-91.

Rosenbröijer, C-J. (1998) Capability development in a business relationship, proceedings of the $14^{\text {th }}$ IMP Conference, Turku School of Economics and Business Administration, Finland.

Ritter, T. (1999) The networking company, Industrial Marketing Management, Vol. 28 No. 5, pp. 497-506.

Ritter, T. (2000) A framework for analyzing interconnectedness of relationships, Industrial Marketing Management, Vol. 29 No. 4, pp. 317-326.

Rumelt, R.P. (1987) Strategy, economic theory and entrepreneurship, in Teece, D. (Ed.) The competitive challenge, Ballinger Books, Cambridge, MA. 
Teece, D. J. (1998) Capturing Value from Knowledge Assets: The New Economy, Markets for Know-How and Intangible Assets, California Management Review, Vol. 40 No.3, Spring.

Teece, D. J., Pisano, G. and Shuen, A. (1997) Dynamic capabilities and strategic management, Strategic Management Journal, Vol. 18 No. 7, pp. 509-533.

Shane, S. (2000) Prior knowledge and the discovery of entrepreneurial opportunities, Organization Science, Vol. 11 No. 4, pp. 448-469.

Walter, A., Ritter, T. and Gemünden, H-G. (2001) Value creation in buyer-seller relationships: theoretical considerations and empirical results from a supplier's perspective, Industrial Marketing Management, Vol. 30 No. 4, pp. 365-377.

Webster, F.E. (1992) The Changing Role of Marketing in the Corporation, Journal of Marketing, Vol. 56 (October 1992), 1-17.

Wernerfeldt, B. (1984) A resource-based view of the firm, Strategic Management Journal, Vol. 5, pp. 171-180.

Wickham, P.A. (2004) Strategic Entrepreneurship, Prentice Hall, Essex.

Wilson, D.T. and Jantrania, S. (1994) Understanding the value of a relationship, AsiaAustralia Marketing Journal, Vol. 2, No. 1, pp. 55-66. 
Wynstra, F. and ten Pierick, E. (2000) Managing supplier involvement in new product development: a portfolio approach, European Journal of Purchasing and Supply Management, Vol. 6 No. 1 pp. 49-57.

Yin, R.K. (2003) Case study research: design and methods, Sage, London.

Zolkiewski, J. and Turnbull, P.W. (2002) Do relationship portfolios and networks provide the key to successful relationship management? Journal of Business and Industrial Marketing, Vol. 17 No. 7, pp. 575-597. 